\title{
Cultivation of methanotrophic bacteria in opposing gradients of methane and oxygen
}

\author{
Ingeborg Bussmann, Monali Rahalkar \& Bernhard Schink \\ LS Mikrobielle Ökologie, Fachbereich Biologie, Universität Konstanz, Konstanz, Germany
}

\begin{abstract}
Correspondence: Ingeborg Bussmann, LS Mikrobielle Ökologie, Fachbereich Biologie, Universität Konstanz, Fach M 654, 78457 Konstanz, Germany. Tel.: +497531 883249; fax: +497531 884047; e-mail:

ingeborg.bussmann@uni-konstanz.de
\end{abstract}

Received 6 July 2005; revised 31 October 2005; accepted 6 November 2005.

First published online 24 January 2006.

doi:10.1111/j.1574-6941.2006.00076.x

Editor: Gary King

\section{Keywords}

freshwater sediment; gradient cultivation; Lake Constance; methanotrophs; Methylobacter; Methylomonas.

\begin{abstract}
In sediments, methane-oxidizing bacteria live in opposing gradients of methane and oxygen. In such a gradient system, the fluxes of methane and oxygen are controlled by diffusion and consumption rates, and the rate-limiting substrate is maintained at a minimum concentration at the layer of consumption. Opposing gradients of methane and oxygen were mimicked in a specific cultivation set-up in which growth of methanotrophic bacteria occurred as a sharp band at either $c .5$ or $20 \mathrm{~mm}$ below the air-exposed end. Two new strains of methanotrophic bacteria were isolated with this system. One isolate, strain LC 1, belonged to the Methylomonas genus (type I methantroph) and contained soluble methane mono-oxygenase. Another isolate, strain LC 2, was related to the Methylobacter group (type I methantroph), as determined by $16 \mathrm{~S}$ rRNA gene and $p m o A$ sequence similarities. However, the partial pmoA sequence was only $86 \%$ related to cultured Methylobacter species. This strain accumulated significant amounts of formaldehyde in conventional cultivation with methane and oxygen, which may explain why it is preferentially enriched in a gradient cultivation system.
\end{abstract}

\section{Introduction}

Methanotrophic or methane-oxidizing bacteria (MOB) are an important group of bacteria that use methane as their sole source of carbon and electrons. There is an increasing interest in $\mathrm{MOB}$ because of their importance in greenhouse gas consumption and their potential application in bioremedial degradation of industrial pollutants, e.g., trichloroethylene (Hanson \& Hanson, 1996). MOB need both methane as electron donor, and oxygen as coreactant in the oxygenase reaction and as electron acceptor. In sediments, methane diffuses upwards from deeper sediment layers, and oxygen diffuses from the water column into the sediment. Both gases overlap at very low concentrations in the top few millimeters below the sediment surface where MOB can live in counter gradients of methane and oxygen. In this narrow zone, methanotrophic growth is limited by the diffusive transport of both substrates.

MOB include species in the Alphaproteobacteria (type II $\mathrm{MOB}$ ) and in the Gammaproteobacteria (type I MOB) (Bowman, 2000). The oxidation of methane to methanol is catalysed by either a soluble or a membrane-associated form of methane mono-oxygenase (sMMO and pMMO, respectively) (Hanson \& Hanson, 1996). The pMMO genes are almost universal in MOB. One gene of this operon, $p m o A$, is strongly conserved and can be used as a functional phylogenetic marker for identification of MOB in general (Holmes et al., 1995).

In profundal sediment of Lake Washington, USA, the enrichment of MOB with mineral medium (Whittenbury et al., 1970) led to the isolation of type I and type II MOB in almost equal numbers (five and six strains out of 11 , respectively). Two sMMO-containing strains were isolated and assigned to the genus Methylomonas, although this type of methanotroph had not been reported before from a pristine environment (Auman et al., 2000). In a further study, it was shown that the major methanotrophic population in Lake Washington sediment consists of sMMOcontaining Methylomonas-like MOB (type I) (Auman \& Lidstrom, 2002). The number of type I MOB in this sediment, as estimated with cultivation-independent methods, is an order of magnitude higher than that of type II MOB (Costello et al., 2002).

In littoral sediment of Lake Constance, Germany, MOB have been investigated by both culture-independent and cultivation-dependent methods. Here, a stable and diverse community of both type I and type II MOB, and an 
apparent dominance of type I MOB could be documented with a terminal restriction fragment length polymorphism (T-RFLP) and pmoA clone library approach (Pester et al., 2004). Attempts to optimize the cultivation conditions by modification of the composition of the medium and the gas atmosphere resulted in increased viable counts, but the diversity of the cultivated MOB still did not represent the diversity of methanotrophs in this sediment (Bussmann et al., 2004).

Intermediates of methane oxidation, such as methanol, formaldehyde and formate, have been detected in methanotrophic cultures, and they may even reach inhibitory concentrations (Agrawal \& Lim, 1984; Costa et al., 2001). The production of formaldehyde and formate is favoured under unbalanced growth conditions if such bacteria are grown with methanol at high concentrations of oxygen. The removal of these intermediates, for example, by a methylotrophic partner organism, increases the methane oxidation rate of MOB (Wilkinson et al., 1974). Another way to avoid self-intoxication of MOB by possibly excreted toxic intermediates is the cultivation of these bacteria in counter gradients of methane and oxygen, as first described by the laboratory of R. Knowles (Amaral \& Knowles, 1995; Amaral et al., 1995).

The aim of our present study was to combine the gradient technique and an optimized mineral medium (Bussmann et al., 2004) for cultivation of novel and ecologically relevant methanotrophs from littoral sediment of Lake Constance. The diversity of MOB growing in the gradients was compared with the total diversity of MOB in Lake Constance sediment on the basis of pmoA clone libraries.

\section{Materials and methods}

\section{Study site and sediment sampling}

Experiments were carried out with sediment from the lower infralittoral zone ('Litoralgarten', $47^{\circ} 41^{\prime} \mathrm{N}, 9^{\circ} 12^{\prime} \mathrm{E}$ ) of Lake Constance, Germany. At the study site, methane concentrations in the sediment ranged from 20 to $90 \mu \mathrm{M}$ at the sediment surface (Bussmann, 2005). The sediment consisted mainly of fine sand with a porosity of 0.62 . Sediment cores (diameter $2.3 \mathrm{~cm}$ ) were taken by SCUBA diving or with a sediment corer (diameter $8 \mathrm{~cm}$ ) at 2-5 $\mathrm{m}$ water depth.

\section{Cultivation of MOB in liquid or on solid media}

Methanotrophs were grown in diluted mineral medium supplemented with a seven-vitamin solution (Widdel \& Pfennig, 1981) and were incubated at 16 or $20^{\circ} \mathrm{C}$ in desiccators under an atmosphere of $17 \% \mathrm{O}_{2}, 24 \% \mathrm{CH}_{4}, 2 \%$ $\mathrm{CO}_{2}$ and balance $\mathrm{N}_{2}$ (Bussmann et al., 2004). Solid media in plates contained $1.2 \%$ agarose. $\mathrm{MOB}$ were also grown in liquid medium in microtiter plates. For positive growth the
$\mathrm{OD}_{595 \mathrm{~nm}}$ had to be 1.5-fold more than the OD of a sterile control. To test for nonmethanotrophic growth, cultures were streaked on plates with diluted complex medium (Bussmann et al., 2001) or Luria-Bertani (LB) agar (Eisenstadt et al., 1984) and incubated without methane. Pure cultures of Methylobacter luteus type I and Methylosinus trichosporium type II (a gift from Peter Dunfield, MPI Marburg, Germany) were grown in liquid nitrate mineral salts (NMS) medium (Whittenbury et al., 1970).

\section{Cultivation of MOB in gradients}

Bacteria were cultivated in glass tubes (inner diameter $8 \mathrm{~mm}$, length $12 \mathrm{~cm}$ ) with screw caps at both ends. They were sealed with polytetrafluoroethylene (PTFE) filters (TE 36, Schleicher \& Schuell, Dassel, Germany) that were supported by perforated silicone septa. Agarose $(0.2 \% \mathrm{w} / \mathrm{v}$; Agarose NEEO, Ultra Quality, Roth, Karlsruhe, Germany) was added to the diluted mineral medium to obtain a semisolid consistency. Tubes were supplied with inoculum, then the anoxic and warm $\left(38^{\circ} \mathrm{C}\right)$ medium was added and mixed immediately.

The incubation chamber carried 42 gradient cultivation tubes and consisted of two chambers (6.5 L volume each) separated by an intermediate bottom which held the cultivation tubes in gas-tight rubber seals. The upper chamber was filled with air and the lower one was flushed for $20 \mathrm{~min}$ (to exchange its volume three times) with $2 \% \mathrm{CO}_{2}, 24 \% \mathrm{CH}_{4}$ and balance $\mathrm{N}_{2}$. The gas mixture was water saturated by passage through a washing flask to prevent evaporation from the tubes. The incubation temperature was either 16 or $20{ }^{\circ} \mathrm{C}$. Tubes were checked once a week for presence of bands, and the gas mixture was renewed accordingly.

To verify if the observed bands were due to growth of $\mathrm{MOB}$, the distribution of oxygen and methane was determined. Dissolved oxygen was measured with a Clark-type microelectrode (Ox50, Unisense, Aarhus, Denmark) at $1 \mathrm{~mm}$ intervals. Methane concentrations were determined with a methane sensor modified after (Rothfuss \& Conrad, 1994).

\section{Isolation of methanotrophs}

Surface sediment (upper $1 \mathrm{~cm}$ ) was used as inoculum. Two millilitres of sediment were mixed with $8 \mathrm{~mL}$ of mineral medium, and then further diluted (nine to 10 steps). These dilutions were used as inoculum $(0.3 \mathrm{~mL})$ for $3 \mathrm{~mL}$ of diluted mineral medium in gradient tubes. The final dilutions ranged from $2 \times 10^{-1}$ to $1 \times 10^{-7}$. Usually four or five replicates were set up for each dilution step, along with controls without methane, without oxygen, and without inoculum. After band formation was observed, the tubes were removed from the box, the agarose column was pushed out with a rubber plunger, and the bands were excised 
aseptically with a sterile scalpel. Bands from replicate tubes of the last positive dilution were pooled, resuspended in liquid mineral medium, and vortexed, and around $500 \mu \mathrm{L}$ was used for inoculation of another 1:10 dilution series with liquid medium. After incubation for 2-3 weeks, the last positive dilution tube was used again for inoculation of another dilution series until finally one morphotype dominated. The last three positive dilutions were streaked on plates and incubated with and without methane. A binocular microscope was used to pick smaller colonies, which were resuspended and streaked on fresh plates until a pure culture was obtained. Isolates were checked frequently for nonmethanotrophic contaminants after streaking on complex media. The cultures were examined with a phase contrast microscope (Axiophot; Zeiss, Oberkochen, Germany) and photographed using a cooled charge-couple device camera (Magnafire, INTAS, Göttingen, Germany). Isolates were maintained at $4{ }^{\circ} \mathrm{C}$ under a methane atmosphere for longer storage.

\section{Alcian blue staining}

Polysaccharides produced after 3 weeks' growth, in liquid or on solid medium or in gradients, were stained with Alcian blue (Hilger et al., 2000). Cell material was scraped from plates, liquid cultures were used directly, and cell material from gradient cultures was cut from bands and suspended in ca. $300 \mu \mathrm{L}$ of liquid mineral medium. Twenty microlitres of 1\% Alcian blue solution in ethanol was diluted 1:10 with deionized water and mixed with c. $20 \mu \mathrm{L}$ of sample. Negative controls were prepared with pure agarose, to check for staining of agarose.

\section{Chemical analyses}

Formaldehyde was analyzed in the gas phase of incubation vessels by gas chromatography. Standards were prepared in glass tubes closed with butyl rubber stoppers. Formaldehyde standards were prepared from a fresh $37 \%$ (weight in volume, w/v) formaldehyde solution (Merck, Darmstadt, Germany) ranging from $0.01 \%$ to $2 \%$ (volume in volume, $\mathrm{v} / \mathrm{v})$. The formaldehyde concentration in the gas phase was estimated according to Grützner \& Hasse (2004) and gas phase-liquid equilibria were calculated according to Flett et al. (1976).

\section{DNA extraction and PCR amplification}

DNA was extracted from cell material by a combination of enzymatic lysis (Ohkuma \& Kudo, 1996) and bead beating (Henckel et al., 1999) with the following modifications: cell material from gradient culture bands $(200-500 \mu \mathrm{L})$ was used for DNA extraction. Colonies were scraped from plates or cell pellets were obtained from 1 to $2 \mathrm{~mL}$ of liquid cultures after centrifugation for $10 \mathrm{~min}$ at $17900 \mathrm{~g}, 4^{\circ} \mathrm{C}$. Cell material was suspended in $800 \mu \mathrm{L}$ buffer $(100 \mathrm{mM}$ Tris $\mathrm{HCl}, \mathrm{pH}$ 8.0, 50 mM EDTA) and homogenized with plastic pestles (Micropistill sticks, Eppendorf, Hamburg, Germany). The homogenates were transferred into screw-cap tubes with $0.7 \mathrm{~g}$ silica beads $(0.1 \mathrm{~mm}$ diameter $)$ and lysozyme $\left(5 \mathrm{mg} \mathrm{mL}^{-1}\right)$. After incubation for $20 \mathrm{~min}$ at $37^{\circ} \mathrm{C}$, proteinase $\mathrm{K}\left(100 \mu \mathrm{g} \mathrm{mL}^{-1}\right)$ was added and the mixture was incubated again at $37^{\circ} \mathrm{C}$ for $40 \mathrm{~min}$. After bead-beating $\left(6.5 \mathrm{~m} \mathrm{~s}^{-1}, 45 \mathrm{~s}\right)$, proteins and debris were removed by washing two times with chloroform: isoamyl alcohol (24:1 $\mathrm{v} / \mathrm{v}$ ) in phase lock gel tubes (Eppendorf). The DNA was finally precipitated with a 0.7 volume of isopropanol and harvested by centrifugation at $20800 \mathrm{~g}$ for $60 \mathrm{~min}$, followed by removing the salts with $70 \%(\mathrm{v} / \mathrm{v})$ ethanol and drying. The DNA was resuspended in $c .50 \mu \mathrm{L} 10 \mathrm{mM}$ Tris-EDTA buffer and stored at $-20^{\circ} \mathrm{C}$. DNA from pure cultures was used for amplification of $16 \mathrm{~S}$ rRNA genes, using $27 \mathrm{f}$ (Edwards et al., 1989)and 1492r (Weisburg et al., 1991) universal primers. DNA from gradient cultures and pure cultures was used for the amplification of partial pmoA gene, using the pmoA primer pair A189f-mb661r (Costello \& Lidstrom, 1999), additionally with isolates, amplification of partial pmoA gene was also checked with primer pair pmoA A189f-A682r (Holmes et al., 1995). For amplification of the $m m o X$ gene, primers mmoXA and mmoXB were used.

For construction of a sediment pmoA clone library, littoral sediment (upper $1 \mathrm{~cm}$ layer) was collected in August 2005. DNA was extracted using PowerSoil ${ }^{\mathrm{TM}}$ DNA Isolation Kit (Mo BIO Laboratories Inc., Solana Beach, CA).

All amplifications were carried out in 50 or $25 \mu$ l total volume in an Eppendorf thermal cycler using recombinant Taq DNA polymerase (Eppendorf) or FailSafe ${ }^{\mathrm{TM}}$ Enzyme Mix and Premix B (Epicentre, Madison, WI) for clone library construction. For amplification of $16 \mathrm{~S}$ rRNA genes, an initial denaturation at $94^{\circ} \mathrm{C}$ for $3 \mathrm{~min}$ was done, followed by 32 cycles at $94{ }^{\circ} \mathrm{C}$ for $30 \mathrm{~s}, 53{ }^{\circ} \mathrm{C}$ for $30 \mathrm{~s}$ and $72{ }^{\circ} \mathrm{C}$ for $1 \mathrm{~min}$, with a final extension step at $72^{\circ} \mathrm{C}$ for $10 \mathrm{~min}$. For amplification with type I and type II methanotroph-specific primers (Wise et al., 1999), as well as for partial pmoA and $m m o X$ genes, the following program was used: initial denaturation at $94^{\circ} \mathrm{C}$ for $3 \mathrm{~min}$, followed by 32 cycles at $94^{\circ} \mathrm{C}$ for $30 \mathrm{~s}, 56^{\circ} \mathrm{C}$ for $1 \mathrm{~min}$ and $72^{\circ} \mathrm{C}$ for $90 \mathrm{~s}$, followed by final extension at $72^{\circ} \mathrm{C}$ for $10 \mathrm{~min}$. PCR products were checked for amplification on 1.5\% agarose gel by electrophoresis.

\section{Clone libraries and restriction fragment length polymorphism}

PmoA clone libraries from sediment and from gradient culture bands were prepared by cloning the partial $p m o A$ gene product $(508 \mathrm{bp})$ obtained after amplification with 
primers A189f-mb661r (Costello \& Lidstrom, 1999) and purification of the PCR products. PCR products were purified using the Qiagen PCR purification kit (Qiagen, Hilden, Germany). All cloning steps were carried out using the TA cloning kit (Invitrogen, Karlsruhe, Germany). In the case of libraries with gradient culture bands, 30 clones from each clone library were selected randomly and were subjected to tooth pick PCR, using primers A189f-mb661r. The amplified products were digested with Msp I (5 U, MBI Fermentas, St Leon-Rot, Germany), separated on 3.5\% NuSieve agarose $\left(\mathrm{NuSieve}^{\mathbb{R}}\right.$ 3: 1 Agarose, Cambrex Bio Science Inc., Rockland, $\mathrm{ME}$ ), grouped according to their restriction patterns, and each clone was assigned to an operational taxonomic unit (OTU) which represented a unique RFLP pattern. Sediment clone libraries were analysed similarly, except more clones, i.e. around 70 clones, were picked randomly to cover the entire diversity, were digested with MspI/HaeIII (5 U, MBI Fermentas) and grouped as described above.

$16 \mathrm{~S}$ rRNA gene clone libraries were constructed with DNA extracted from gradient bands. DNA was PCR amplified with the universal bacterial primers $27 \mathrm{f}$ (Edwards et al., 1989) and 1492r (Weisburg et al., 1991) and cloned separately as described above. Clones were digested with MspI restriction enzymes, RFLP analysis was done, and OTUs were assigned as described above.

\section{Cloning, sequencing and phylogenetic analysis}

With our isolates strains LC 1 and LC 2, complete 16S rRNA gene sequences were obtained by cloning the fragments using the TA cloning kit (Invitrogen). Clones were sequenced with primers $27 f$ (Edwards et al., 1989), $533 f$ (Lane et al., 1985), 1492r (Weisburg et al., 1991) and MethT1dR (Wise et al., 1999), and were assembled using the DNAStar software (http://www.dnastar.com). Similarly, sequences of the partial pmoA gene of the isolates and the partial $m m o X$ gene of strain LC 1 were obtained by direct sequencing of the PCR products, and a complete sequence was obtained after cloning the fragment using the TA cloning kit and sequencing from both ends.

In the case of pmoA and 16S rRNA gene clone libraries, representative clones from each OTU group were sequenced. At least $10 \%$ of clones from each RFLP group were sequenced. $p m o A$ and $m m o X$ clones were sequenced using M13f and M13r primers. Representative clones from the $16 \mathrm{~S}$ rRNA gene clone library were either sequenced completely with 27f (Edwards et al., 1989), or 1492r (Weisburg et al., 1991) (clones representing dominant OTU groups) or partially with the $27 \mathrm{f} \mathrm{primer} \mathrm{(clones} \mathrm{that} \mathrm{were} \mathrm{less} \mathrm{frequent).}$ All sequencing reactions were carried out at GATC Biotech AG (Konstanz, Germany). A BLAST search was performed at the NCBI site (http://www.ncbi.nlm.nih.gov/) (Altschul et al., 1990) and closely related sequences were retrieved. All sequences were checked for chimeras by dividing the sequence in two partial sequences and performing a BLAST search. Two chimeras were found in 16S rRNA gene clone libraries.16S rRNA gene sequences of strains LC 1 and LC 2 were phylogenetically analysed using the ARB software package (version 2.5b; http://www.arb-home.de) (Ludwig et al., 2004). The new sequences were added to the ARB database and aligned using the FAST Aligner tool as implemented in ARB. Alignments were checked and manually corrected where necessary. Sequences with more than 1400 nucleotides were used for alignment. Only those positions which were identical in 50\% of all sequences were used to create a filter. Phylogenetic analysis was done using the maximum likelihood, neighbour-joining and maximum parsimony algorithms as implemented in ARB. Phylogenetic distances were determined by calculating the similarity matrix within ARB using Escherichia coli $16 \mathrm{~S}$ rRNA gene as filter.

For phylogenetic analysis, $p m o A$ gene sequences were translated within ARB to obtain deduced amino acid sequences, and phylogenetic distance dendrograms were constructed using different methods such as neighbourjoining, Desoete, and PHYLIP with the Fitch and Margoliash method (Felsenstein, 1989). Representative sequences of pmoA clones and isolates obtained in earlier studies done on Lake Constance as well as in other studies were used (Pester et al., 2004).

All sequences have been deposited in GenBank under accession numbers DQ119042-DQ119051 (sequences from gradient clones and isolates) and DQ235456-DQ235470 (sequences from sediment pmoA clone library).

\section{Results}

\section{Growth of MOB in gradient cultures}

Initial experiments had shown that gradients of oxygen (and we assume also methane gradients) establish within 3-4 days in a $4.5 \mathrm{~cm}$ agarose column.

Enrichment cultures from sediment developed $0.5 \mathrm{~mm}$ thick bands of bacterial growth after 2-3 weeks of incubation. A narrow, homogeneous band, rather than single colonies, was taken as an indication of methanotrophic growth in gradient tubes, as described in Amaral \& Knowles (1995). If methane was excluded from the tubes, such bands were never observed. Bands occurred typically c. $5 \mathrm{~mm}$ below the air-exposed end, ranging from 2 to $5 \mathrm{~mm}$. In some cases, a thin band was observed at c. $20 \mathrm{~mm}$ below the air-exposed end, ranging from 20 to $25 \mathrm{~mm}$. In older enrichment culture tubes ( $>4$ weeks), further bands developed like shadows below the first band. The distribution of oxygen and methane in these gradients was also measured 
(a)

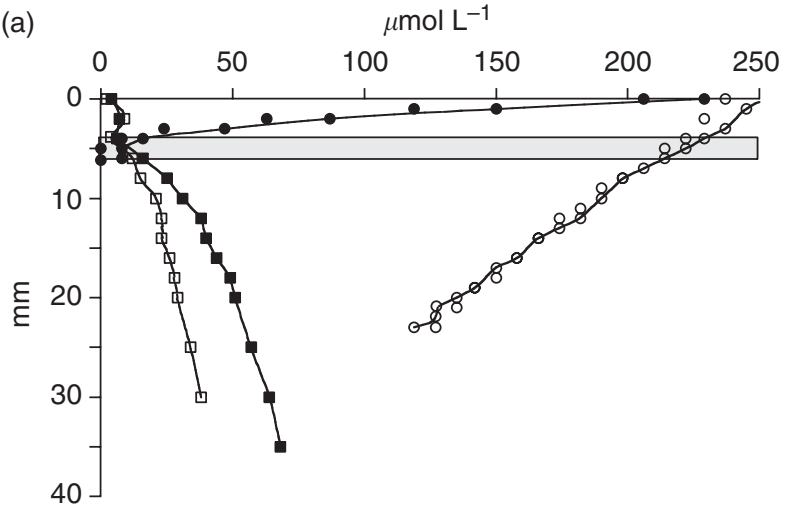

(b)

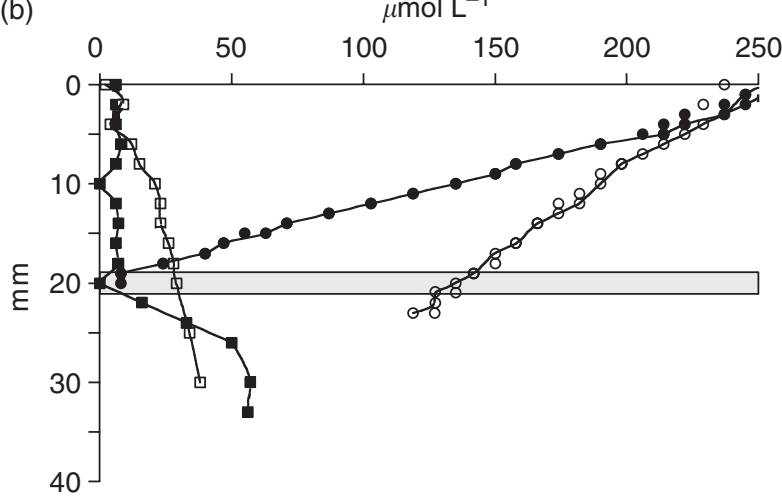

Fig. 1. Gradients of methane (squares) and oxygen (circles) in gradient cultures of (a) strain LC 1 B) strain LC 2. Filled symbols indicate grown cultures; open symbols indicate the sterile control tubes. The position of the band is shown as a shaded area.

(Fig. 1). Oxygen penetrated only to the depth of the growth band ( 5 or $20 \mathrm{~mm}$ ), and methane was not detectable above the bands. In sterile control tubes, oxygen penetrated much deeper into the column and methane reached the surface. Thus, the growth bands were always observed where the concentrations of oxygen and methane approached zero.

Subsequent transfers of the bands into new gradient tubes were often not successful. After the fourth transfer, growth or band could not be observed anymore. We performed various experiments to check for possible reasons for this failure.

Enrichments in the gradient tubes were started with the medium optimized for MOB growing in liquid cultures. Therefore, we checked if the MOB growing in the gradient tubes preferred a different medium composition. Cell material from two to three bands from initial sediment enrichments was pooled, and aliquots were transferred into the same medium again or into modified media. After incubation for 3 weeks, tubes were checked for growth bands. Each medium modification was tested three times. Increasing the phosphate and nitrate content $\left(150 \mu \mathrm{M} \mathrm{K}-\mathrm{Na}-\mathrm{PO}_{4}, 50 \mu \mathrm{M}\right.$
$\mathrm{NO}_{3}$ ) to two-, five- or 10 -fold did not result in better growth. The addition of organic supplements (seven-vitamin solution, $0.05 \%$ yeast extract, or $0.05 \%$ prefermented yeast extract), different buffers (0.01 M 3-(N-morpholino)propanesulphonic acid (MOPS), 0.01 M N-Tris(hydroxymethyl)methyl-2-aminoethanesulphonic acid (TES) or $0.01 \mathrm{M} \mathrm{K}-\mathrm{Na}-\mathrm{PO}_{4}$ ) and different mineral composition (standard medium, full-strength medium according to Widdel (1988), medium according to Whittenbury et al. (1970) or Heyer et al. (1984) had no influence on growth of transferred cultures.

Cultures of $\mathrm{MOB}$ that had always been cultivated in liquid or solid medium were checked for growth in gradient cultures. Exponentially growing liquid cultures of Methylobacter luteus and Methylosinus trichosporium were inoculated: (i) into freshly prepared liquid medium with warm agarose; (ii) into already solid medium in tubes stored under nitrogen; (iii) on the surface of solid medium with a 3-dayold gradient; or (iv) $5 \mathrm{~mm}$ below the surface of solid medium with a 3-day-old gradient. Both strains grew in the gradient tubes. The bands looked sharpest and most homogenous when inoculated into freshly prepared medium.

In an additional experiment, we tested how many cells of MOB were necessary to form a band in gradient tubes, compared to formation of turbidity in a microtiter plate. An exponentially growing culture of $M$. trichosporium was counted microscopically and diluted in 1:2 steps down to 3 cells $\mathrm{mL}^{-1}$. Aliquots were transferred into gradient tubes $(3 \mathrm{~mL})$ and into microtiter plates $(240 \mu \mathrm{L})$ resulting in the same cell number per vial. Gradient tubes were incubated in the incubation chamber and the microtiter plates in a desiccator, both with three parallels per dilution step. No growth was observed with fewer than seven cells per gradient tube $\left(2\right.$ cells $\left.\mathrm{mL}^{-1}\right)$ and fewer than two per cells microtiter well $\left(9\right.$ cells $\left.\mathrm{mL}^{-1}\right)$.

To estimate the number of MOB in the sediment, most probable number (MPN)-counting was done in gradient tubes and in liquid culture. For the gradient tubes five to 10 dilution steps with three or four parallels each and for the liquid cultures 12 dilutions with eight parallels each were used (Bussmann et al., 2004). This experiment was repeated twice. At both sampling dates the highest counts were obtained with liquid cultures in microtiter plates, 1.2 and $5.1 \times 10^{4}$ cells $\mathrm{mL}^{-1}$, respectively. The number of MOB ob-

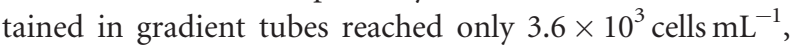
on both dates.

\section{Isolation of methanotrophs from gradients}

Isolation of $\mathrm{MOB}$ from gradient enrichment cultures by streaking on plates led mostly to type I MOB. We describe here some of the strains isolated by the gradient cultivation technique. 


\section{Lake constance Isolate 1 (Strain LC 1)}

Strain LC 1, a type I methanotroph, was isolated from a gradient enrichment culture obtained from a $1.6 \times 10^{-3}$ dilution of the sediment. Strain LC 1 was isolated on solid medium, but it grew also in gradient culture and formed a band usually c. $5 \mathrm{~mm}$ below the air-exposed end (Fig. 1a). LC1 is a motile, fat rod and belongs to the type I MOB, as indicated by phylogenetic analysis of the $16 \mathrm{~S}$ rRNA gene sequence. It is closely related to Methylomonas methanica (99.4\%) and Methylomonas sp. LW15 (99.5\%) that were isolated from Lake Washington (Fig. 2). The interesting feature of our strain is that the partial $p m o A$ gene cannot be amplified with the $p m o A$ primer A189f-A682r, but only with primer A189f-mb661r. (A weak band is obtained at lower annealing temperatures if primer A178f-A682r is used.) The sequence of the product obtained with A189-mb661 shows 95\% nucleotide identity with the pmoA sequence of Methylomonas sp. LW15 (Fig. 3). As strain LC 1 is closely related to Methylomonas sp. LW15, it was tested for the presence of sMMO with the primers mmoXA and mmoXB (Auman \& Lidstrom, 2002). Strain LC 1 showed a positive PCR product of correct length $(1230 \mathrm{bp})$. The sequence of the PCR product showed 94\% nucleotide identity with the corresponding fragment in the Methylomonas LW15 mmoX gene.

\section{Lake constance isolate 2 (Strain LC 2)}

Strain LC 2, a type I methanotroph, was isolated from a gradient enrichment culture obtained from an $8 \times 10^{-3}$ dilution of the sediment. The pale pink colonies were slimy with an aqueous consistency. They maintained their consistency after repeated streaking on mineral medium with agarose, but their size decreased after successive transfers. Cells were actively motile, large, coccoid to oval in shape and sometimes changed to ellyptical or rod-like shape, $1-2 \times 2-3.5 \mu \mathrm{m}$ in size (Figs $4 \mathrm{a}, \mathrm{b}$ ). They were surrounded by capsular material, were fragile and bursted easily upon applying little force to the cover slip.

On solid mineral medium, mucoid colonies grew within 2-3 weeks at $16-20^{\circ} \mathrm{C}$. Old plates often smelled of formaldehyde, and the presence of formaldehyde in the gas phase (0.3-0.7 vol\%) was confirmed by gas chromatograph analysis of unopened desiccators in which this bacterium was growing. When grown in closed glass vessels, formaldehyde

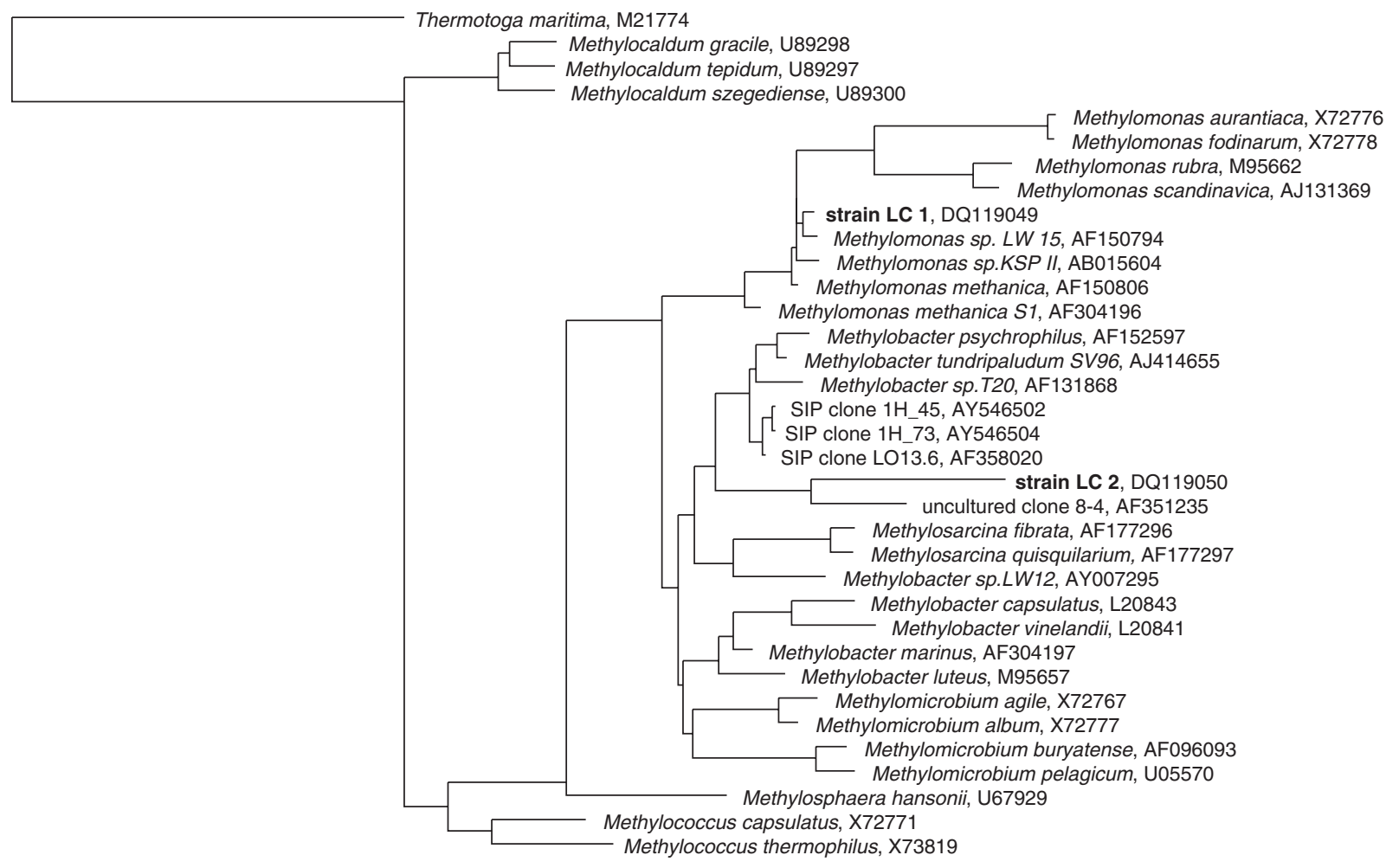

0.10

Fig. 2. Maximum likelihood analysis of $16 \mathrm{~S}$ rRNA gene sequences of strain LC 1 and LC 2 (with their accession numbers) in comparison to cultured members and clones from various studies. Clones from various SIP experiments are prefixed with SIP clone. The NCBI-accession numbers of clones and strains from other studies are written by each name. 


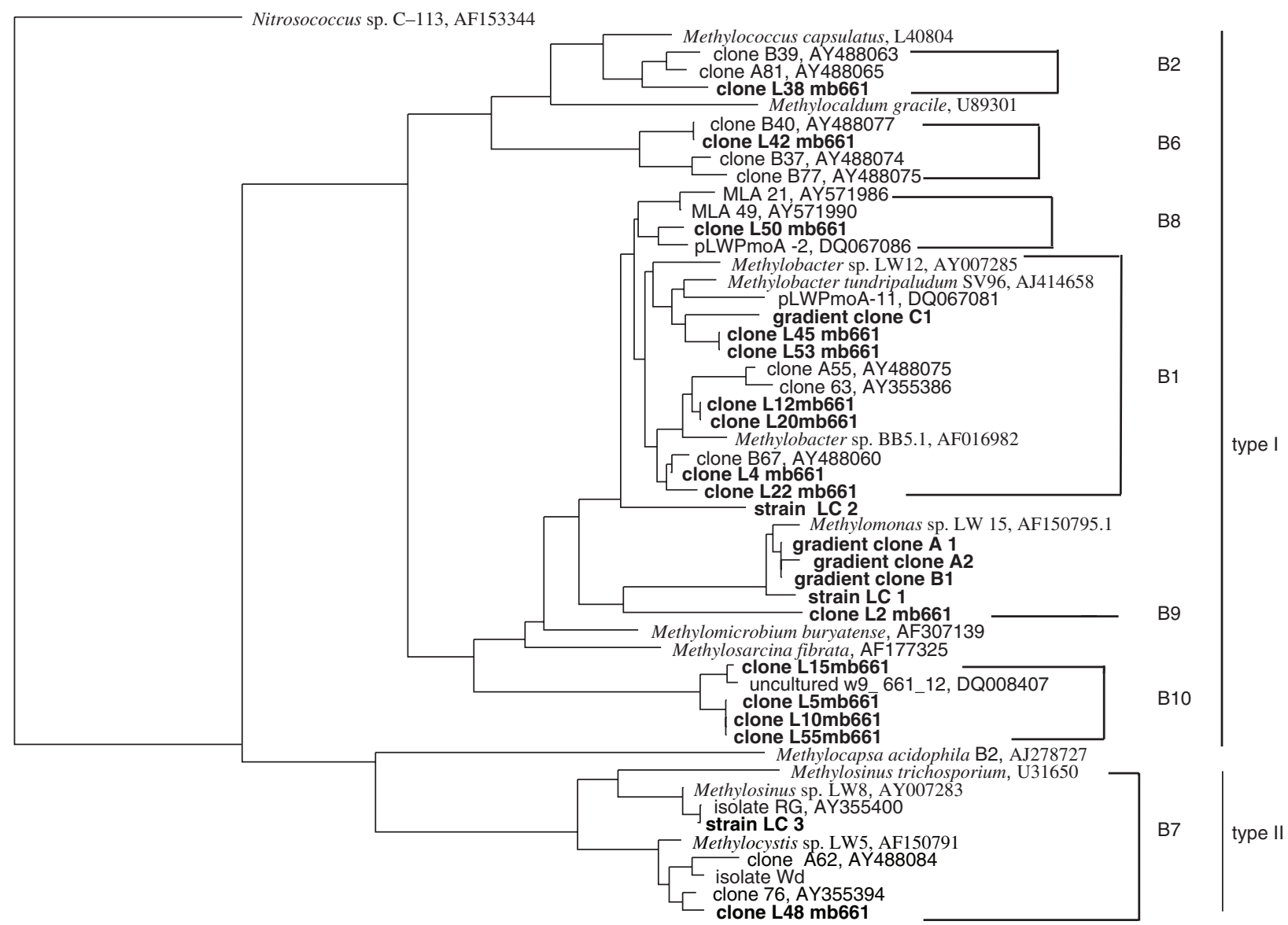

0.10

Fig. 3. Phylogenetic dendrogram based on the derived amino acid sequences of pmoA genes showing the position of strains isolated in this study (bold), clones from gradient cultures ('gradient clone', bold), sediment pmoA clones in this study (bold) and named as clone L'mb661, clones and strains from previous studies on Lake Constance (Bussmann et al., 2004; Pester et al., 2004) and pmoA sequences of few cultured and uncultured methanotrophs. NCBI accession numbers from other studies are given along with the names or clone numbers. The tree was constructed using the neighbour-joining method as implemented in the ARB software and was based on 160 amino acids. The bar represents $10 \%$ divergence.

was produced in the range $0.06-1.4 \mathrm{vol} \%$ in the gas phase, corresponding to $0.05-1.2 \mathrm{mM}$ in the culture liquid.

In liquid culture, strain LC 2 grew as a thin biofilm attached to the bottom of the glass tube. If the tube was vortexed the biofilm broke up into threads or fragments. Liquid cultures consisted mainly of chains or groups of cells.

In gradient cultures, strain LC 2 usually formed a band at 20-22 $\mathrm{mm}$ distance from the air-exposed end. Occasionally an early lower band appeared after 10-12 days, and thus two bands were seen after 20 days of incubation at $16^{\circ} \mathrm{C}$ (Fig. 4c). At the position of the band, methane disappeared and oxygen was only present above (Fig. 1b). Both bands were sliced and observed under a microscope. They contained cell aggregates and the cells were much larger compared to those grown on solid or in liquid medium of similar age. The average size of cells grown in gradients was $2.5 \mu \mathrm{m}$ in diameter, whereas in liquid or on solid medium the average cell diameter was $1.5 \mu \mathrm{m}$. Whereas cells grown in liquid or on solid medium produced ample amounts of extracellular polymeric substances staining with Alcian blue, cells grown in gradients carried very few such extracellular polymers (not shown).

A nearly full-length (around $1400 \mathrm{bp}$ ) 16S rRNA gene sequence was obtained by direct sequencing of the $27 \mathrm{f}-1492 \mathrm{r}$ PCR product with 27f, $1492 \mathrm{r}$ and MethT1df primers. To obtain the complete sequence of $1492 \mathrm{bp}$, the 16S rRNA partial gene was cloned and sequenced. All methods of tree construction applied yielded trees of similar topology. Strain LC 2 was distantly related to Methylobacter sp. (Fig. 2). The closest cultured relatives of this strain are psychrophilic methanotrophs, Methylobacter psychrophilus (Tourova 
(a)

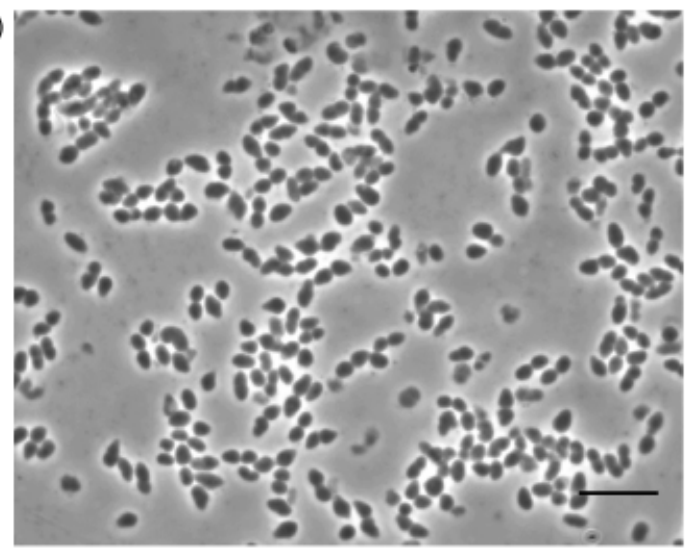

(b)

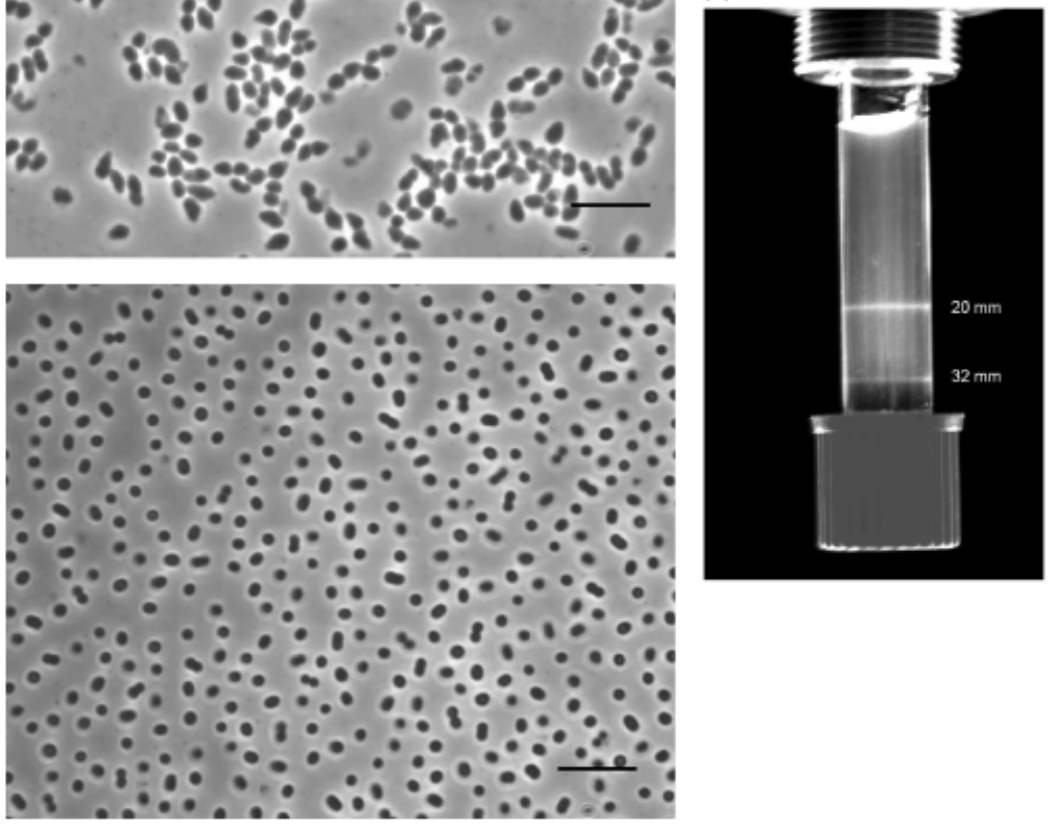

(c)
Fig. 4. Morphology of strain LC 2. (a) Phase contrast photomicrograph of rod-shaped to elliptical cells, (b) phase contrast photomicrograph of coccoid cells and (c) of cells grown in gradient culture. The bar represents $10 \mu \mathrm{m}$. et al., 1999) and Methylobacter tundripaludum SV 96 species (Wartiainen et al., 2005), with $92.7 \%$ and $93.4 \%$ similarity, respectively (Fig. 2). The strain also contained a $p m o A$ gene which could be amplified by both primer pairs (A189fA682r, A189f-mb661r). The partial pmoA sequence of 530 bp was at the nucleotide level only $86 \%$ identical with that of cultured Methylobacter species, Methylobacter sp.BB5.1 and Methylobacter sp. LW12, and did not have an Msp I enzyme restriction site. It showed a distinct position in the phylogenetic tree, close to the Methylobacter pmoA sequences (Fig. 3).

\section{Isolated type II methanotrophs}

Two type II methanotrophs were also isolated from the gradient cultures enriched from two different sediment samples. Strains LC 3 and LC 4 were assigned to strains of Methylosinus sporium, by comparison of the sequence of the partial $p m o A$ gene. Strains LC 3 and LC 4 had identical $p m o A$ sequences which are very similar to Methylosinus sporium strain RG, a strain previously isolated from Lake Constance (Bussmann et al., 2004), and
M. sporium SE 2. These strains were not characterized any further.

\section{Bacterial diversity in the growth bands}

To estimate the methanotrophic diversity in the growth bands, three $p m o A$ clone libraries were constructed (Table 1). Clone libraries constructed from bands A and B were dominated by sequences similar to $p m o A$ sequences of strain LC 1 or of Methylomonas sp. LW15 (Fig. 3). These gradient clones (A1, A2 and B1) were close to sediment clone group B9. Bands A and B were formed at 5 and $3 \mathrm{~mm}$ from the airexposed end of the tube, respectively. The third clone library was prepared from band C, which was $45 \mathrm{~mm}$ from the airexposed end. This library was dominated by a single group (gradient clone $\mathrm{C} 1$ ), which was within the most dominant sediment clone group B1 (Fig. 3).

To estimate the overall bacterial diversity in these growth bands 16S rRNA gene clone libraries were constructed from the DNA of bands B and C. In band B a high bacterial diversity was found. Methanotrophic bacteria represented only $20 \%$ of the clone library (99\% similar to strain LC 1 
Table 1. pmoA clone libraries obtained from gradient culture bands

\begin{tabular}{|c|c|c|c|c|c|}
\hline $\begin{array}{l}\text { Gradient culture } \\
\text { bands }\end{array}$ & $\begin{array}{l}\text { Sampling date } \\
\text { and incubation } \\
\text { temperature }\end{array}$ & Dilution & $\begin{array}{l}\text { Approx. distance } \\
\text { from air-exposed } \\
\text { end }(\mathrm{mm})\end{array}$ & $\begin{array}{l}\text { Relative abundance } \\
\text { of RFLP group }\end{array}$ & Nucleotide similarity* \\
\hline $\mathrm{A}^{\dagger}$ & May $2004,20^{\circ} \mathrm{C}$ & $3 \times 10^{-4}$ and $1 \times 10^{-5}$ & 5 & $\begin{array}{l}88.6 \%, \text { gradient clone } \mathrm{A} 1 \\
5.8 \%, \text { gradient clone } \mathrm{A} 2\end{array}$ & $\begin{array}{l}\text { 95-97\% Methylomonas sp. } \\
\text { 95-97\% Methylomonas sp. }\end{array}$ \\
\hline $\mathrm{B}^{\dagger}$ & Sept $2004,20^{\circ} \mathrm{C}$ & $8 \times 10^{-3}$ & 3 & $100 \%$, gradient clone B1, & 95-97\% Methylomonas sp. \\
\hline $\mathrm{C}^{\dagger}$ & July $2004,20^{\circ} \mathrm{C}$ & $8 \times 10^{-3}$ & 45 & $100 \%$, gradient clone $\mathrm{C} 1$ & 92\% Methylobacter SV 96 \\
\hline
\end{tabular}

*By NCBI BLAST.

${ }^{\dagger}$ Primers A189f-mb661r were used for all clone libraries.

Table 2. Relative abundance of methanotrophic groups based on frequencies of $p m o A$ genes in clone libraries from littoral sediment

\begin{tabular}{|c|c|c|c|c|}
\hline $\begin{array}{l}\text { Phylogenetic } \\
\text { group }\end{array}$ & Clone group & No. of clones & $\begin{array}{l}\text { Relative } \\
\text { abundance (\%) }\end{array}$ & Next relative (sequence identity) \\
\hline \multirow[t]{6}{*}{ Type I } & $\mathrm{B} 1^{*}$ & 42 & 66 & Clones B67, A55, clone 63 Pester et al. (2004)(91-99\%) \\
\hline & $\mathrm{B} 2 *$ & 2 & 3 & Clones B9, A81, B39 Pester et al. (2004 )(91-97\%) \\
\hline & $B 6^{*}$ & 1 & 2 & Clones B40, B77 Pester et al. (2004 )(92-97\%) \\
\hline & $\mathrm{B}^{\dagger}$ & 2 & 3 & pLWPmoA-2 (Nercessian, et al. 2005) (92\%) \\
\hline & $\mathrm{Bg}^{\dagger}$ & 3 & 5 & $\begin{array}{l}\text { PLWPmoA-11 (Nercessian, et al. 2005) (84\%), } \\
\text { Methylobacter BB5.1 (84\%), Methylomonas sp. LW15 (83\%) }\end{array}$ \\
\hline & $\mathrm{B} 10^{\dagger}$ & 8 & 13 & W9_661_12, clone 9_661_3 Erwin et al. (2005 )(86\%) \\
\hline Type II & $B 7^{*}$ & 6 & 9 & Clone 76 Bussmann et al. (2004)(99\%) \\
\hline
\end{tabular}

*As identified in Pester et al. (2004)

†New groups identified in this study.

and Methylomonas sp. LW15). The clone library was dominated by Flavobacteria (48\% of the clone library) and Betaproteobacteria similar to Pseudomonas saccharophila (17\% of the clone library). In contrast, the $16 \mathrm{~S}$ rRNA gene clone library from band $\mathrm{C}$ showed less bacterial diversity. Here, a methanotroph dominated the clone library with $80 \%$, and the sequence was $98 \%$ close to Methylobacter tundripaludum SV96 by BLAST search. The remaining 20\% were represented by Betaproteobacteria (similar to P. saccharophila).

\section{Methanotrophic diversity in the sediment}

pmoA clone libraries were constructed using DNA from littoral sediment of Lake Constance. These libraries were prepared using the A189f-mb661r primers. The sequences obtained in this library were compared to sequences obtained in an earlier study (Pester et al., 2004), which were prepared using A189f-682r primers. A total of 64 clones with the correct insert size were divided into eight clone groups after phylogenetic analysis (Fig. 3). Most of the clone groups were the same as identified before (Pester et al., 2004), and were named in the same manner (Table 2). These groups were B1, B2, B6 (type I MOB) and B7 (type II MOB), whereas some new groups B8, B9 and B10 (type I MOB) were identified in the present study. Clone group B1 was the most dominant clone group with $65.5 \%$ of relative abundance. Clone group B8 was closely related to clones from Mono Lake, California, USA (Lin et al., 2005), and Lake Washington (O. G. Nercessian, et al., unpublished data). Clone group B9 was only distantly related to known methanotrophs (Table 2) but grouped close to the branch where Methylomonas sp. LW15, strain LC1 pmoA and gradient clones A1, A2 and B1 were present. Clones from group B 10 were not closely related to any cultured methanotroph but related to clones from a river plain aquifer (Erwin et al., 2005).

\section{Discussion}

\section{Growth of MOB in gradients}

Based on a previous study (Amaral \& Knowles, 1995), we describe here a cultivation system for methanotrophic bacteria that allows the incubation of numerous culture tubes in opposing gradients of methane and oxygen, thus mimicking life conditions of methanotrophs in sediments. Methanotrophs grew as bands instead of single colonies in the semi-solid agarose medium. Two types of growth band of methanotrophic bacteria occurred, one growing approx. $5 \mathrm{~mm}$ below the air-exposed end and a lower one approx. 20 or $40 \mathrm{~mm}$ from the air-exposed end. The upper bands 
Table 3. Position of, and flux of oxygen and methane to methanotrophic bands growing in gradient tubes

\begin{tabular}{lllll}
\hline Culture & $\begin{array}{l}\text { Approx. position of } \\
\text { the band }(\mathrm{mm})\end{array}$ & $\begin{array}{l}\text { Oxygen flux* } \\
\left(\mathrm{nmol} \mathrm{h} \mathrm{Cm}^{-2}\right)\end{array}$ & $\begin{array}{l}\text { Methane flux } \\
\left(\mathrm{nmol} \mathrm{h}^{-1} \mathrm{~cm}^{-2}\right)\end{array}$ & $\begin{array}{l}\text { Flux ratio } \\
\left(\mathrm{O}_{2} / \mathrm{CH}_{4}\right)\end{array}$ \\
\hline Strain LC 1 & 5 & 8.6 & 2.8 & 3.0 \\
Sediment enrichment $^{\dagger}$ & 5 & 7.9 & 1.7 & 4.8 \\
Strain LC 2 $^{\dagger}$ & 20 & 9.5 & 4.3 & 2.2 \\
Sediment enrichment $^{\ddagger}$ & 22 & 8.1 & 3.9 & 2.1 \\
\hline
\end{tabular}

*Fluxes were calculated according to Fick's first law of diffusion ( $F=-\varnothing \times D s \times \mathrm{dc} / \mathrm{d} z)$, with the porosity $\varnothing \approx 1$, diffusion coefficient $D s_{\mathrm{O}_{2}}$ or $\mathrm{CH}_{4}=2.3$ or $1.9 \times 10^{-5} \mathrm{~cm}^{2} \mathrm{~s}^{-1}$, change of oxygen or methane concentration versus depth $(\mathrm{d} c / \mathrm{dz})$.

†See Fig. 1.

DData not shown.

consisted of type I and type II MOB, but were usually dominated by type I MOB related to Methylomonas spp., as revealed by pmoA clone library analysis (Table 1), 16S rRNA gene library studies, and by fluorescence in situ hybridization studies (M. Rahalkar, unpublished data). Amaral \& Knowles (1995) described only type I MOB at this position. Also, the known methanotrophs Methylosinus trichosporium (type II) and Methylobacter luteus (type I) both grew at the upper position, as did strains LC 3 and LC 4 (Methylosinus sporium strains, type II). The lower band, c. 20 or $40 \mathrm{~mm}$ from the air-exposed end, consisted only of type I MOB related to the Methylobacter group (Table 1). Amaral \& Knowles (1995) described a rare occurrence of such a lower band that was dominated by type II methanotrophs. This discrepancy may be due to the use of different inocula (freshwater sediment vs. swamp and humisol samples), and different gas concentrations applied to the gradients.

The methane flux was higher to the lower bands with only type I MOB than to the upper bands with types I and II, whereas the oxygen flux to both bands was similar (Table 3 ). It is assumed that type II MOB are dominant at high methane concentrations, and that type I MOB dominate at rapidly changing growth conditions (Graham et al., 1993; Macalady et al., 2002). However, a more detailed study on rice soil showed that there is no clear prevalence of type I or type II populations at different regimes of methane concentration (Henckel et al., 2000). Type I MOB appear to be more flexible, and were present at both positions in our study. The oxygen-to-methane flux ratio was 2.1 and 2.2 in the bands at the lower position in gradient cultures of strain LC 2 and of a sediment enrichment (Table 3). This is close to the theoretical ratio of two, suggesting that methane was completely oxidized to carbon dioxide. However, for most methanotrophic cultures and also for gradient enrichment cultures ratios of 1.6-1.8 were reported (Amaral \& Knowles, 1995), reflecting the fact that substantial amounts of methane are assimilated after incomplete oxidation (Joergensen \& Degn, 1983). The upper bands observed in sediment enrichments exhibited higher oxygen-to-methane ratios, which might be due to utilization of hydrolysed agarose constituents or exudates of the MOB. The presence of oxygen-consuming, heterotrophic bacteria in the upper bands is also supported by the higher bacterial diversity in the upper bands, as shown by the $16 \mathrm{~S}$ rRNA gene clone library.

For growth in gradients it is essential that bacteria are motile to reach their optimal position in the gradient. Motility also allows the bacteria to adjust their position whenever the substrate supply changes. All the isolated strains in this study were motile, as observed microscopically, and as this is known for most strains of MOB (Hanson et al., 1991). This may also be the reason why no Methylocystis (type II) or Methylococcus (type I) strains, which are nonmotile, were isolated (Bowman, 2000).

Unfortunately, at least after the fourth transfer from gradient tube to gradient tube, bacteria stopped growing. The reasons for this were checked (medium composition, inoculum size, transfer procedure), but the problem could not be solved. The gradient system was therefore used only for initial enrichment, and switched for isolation to a 'conventional' cultivation procedure. Nonetheless, all isolated strains could grow again in gradients, as did some tested strains from culture collections.

The oxidation of methane to $\mathrm{CO}_{2}$ proceeds through methanol and formaldehyde, which may be bound to various carriers for further oxidation to a formyl derivative (Vorholt, 2002). The equilibrium of methanol oxidation with pyrroloquinoline quinone or cytochrome $c$ as electron acceptor is far on the side of formaldehyde. Thus, it is not surprising that formaldehyde is accumulated by methaneoxidizing bacteria under excess supply with methane and oxygen, and this was found also with our strain LC 2 during growth on solid medium plates. So far, formaldehyde production $(0.2-7 \mathrm{mM})$ by methanotrophs was reported only during growth at high methanol and oxygen concentrations (Agrawal \& Lim, 1984; Costa et al., 2001). Formaldehyde becomes inhibitory at concentrations between $1 \mathrm{mM}$ (Hou et al., 1978) and $7 \mathrm{mM}$ (Costa et al., 2001). Thus, the amount of formaldehyde produced by strain LC 2 (up to $1 \mathrm{mM}$ ) could be sufficient to inhibit growth of this bacterium, and other strains might be even more sensitive to this toxic compound. 
Methanotrophs are known to produce copious amounts of exopolymeric substances (EPS) (Hou et al., 1978; Linton et al., 1986). For mixed MOB cultures in compost, the highest EPS production was reported at high oxygen levels (10.5\% vs. $1.5 \% \mathrm{O}_{2}$ ) (Wilshusen et al., 2004). EPS can act as a micro-scale diffusion barrier, as the apparent diffusion coefficient can be 50-fold smaller than that of an aqueous solution (Guiot et al., 2002). In landfill cover soil EPS impeded oxygen diffusion to an active biofilm and limited the extent of methane oxidation (Hilger et al., 2000) and EPS formation has been observed also as a response to stress caused by exposure to toxic substances such as detergents (Schleheck et al., 2004; J. Klebensberger et al., personal communication). On the other hand, EPS production can impair growth because of the energy cost involved (Kreft \& Wimpenny, 2001). Our strain LC 2 produced EPS mainly when grown on solid or in liquid medium, perhaps as a means to protect the cells from oxygen stress, and only little EPS was formed during growth in gradient tubes. The absence of formaldehyde and EPS formation, along with increased cell size in gradient cultures of strain LC 2, indicate that under these conditions the diffusion-limited access to methane and oxygen avoids oxygen stress and helps to prevent self-intoxication.

\section{Isolation of methanotrophic bacteria}

Gradient cultivation was described first by Knowles et al. as a novel enrichment culture technique for the growth of methanotrophs (Amaral \& Knowles, 1995). Only one isolate, Methylobacter sp. T 20, obtained by such enrichment has been described (Ren et al., 2000). Our study demonstrates a further strategy that could be used for isolation of methanotrophic bacteria from aquatic habitats. As methanotrophs were associated with other bacteria, it was difficult to isolate them directly in gradient cultures, so initial enrichment in gradients was used, followed by subsequent transfers into liquid or on solid medium.

Strain LC 1 is phylogenetically closely related to Methylomonas methanica and Methylomonas sp. LW15, which both were isolated from Lake Washington (Auman et al., 2000). Methylomonas sp. LW15 possesses the enzyme sMMO, which has been found in few type I MOB, for example, Methylomonas strains from oil- or trichloroethylene (TCE)contaminated sites, as well as from Lake Washington, i.e. a freshwater habitat (Auman \& Lidstrom, 2002). Strain LC 1 possesses sMMO, as confirmed by PCR amplification of the partial mmoX gene, which encodes the $\alpha$ subunit of the hydroxylase component of sMMO. This gene has been used as a biomarker for sMMO (McDonald et al., 1995; Shigematsu et al., 1999; Auman et al., 2000). In addition, strain LC 1 has also the exact match for the rmonas $3 X$ probe (860-879 bp) which was an oligonucleotide probe designed specifically for sMMO-containing Methylomonas strains in a study on Lake Washington (Auman \& Lidstrom, 2002). Hybridisation studies suggested that Lake Washington sediment is dominated by sMMO-containing Methylomonaslike type I methanotrophs (Auman \& Lidstrom, 2002). Thus, we isolated a sMMO-containing type I MOB, which had not yet been described for Lake Constance but which might be a dominating MOB here as well.

Strain LC 2 represents a novel lineage in the phylogenetic tree of type $\mathrm{IMOB}$, and is present on a branch close to that of psychrophilic MOB, such as Methylobacter psychrophilus or the newly described Methylobacter tundripaludum SV96 (Wartiainen et al., 2005) (Fig. 2). This phylogenetic branch also contains Methylobacter sp. T20, which is the only methanotroph previously isolated from a gradient culture (Ren et al., 2000). Other members present on this branch are mostly methanotrophic clones from various stable-isotopeprobing experiments. A $16 \mathrm{~S}$ rRNA gene similarity of $92-93 \%$ of strain LC 2 with known species indicates its novelty. The $p m o A$ sequence is also novel and more related (89\%) to pmoA clones MLA-49, MLA-39 etc. which were isolated from Mono Lake, California, USA (Lin et al., 2005), clones B67, 63 and A55 from Lake Constance (Pester et al., 2004), and only 83-86\% related to cultivated Methylobacter species. The amino acid similarities are $91 \%$ similar to Methylobacter sp. LW 12 and Methylomicrobium buryatense, and 93\% similar to clones B67 and A55 from Lake Constance littoral sediment.

Morphologically similar bacteria have been observed and enriched from Russian arctic Tundra regions (Berestovskaya et al., 2002). These have been described as morphotype 2, which are cocci of $2-2.5 \mu \mathrm{m}$ diameter, with mucous capsules, preferred growth temperatures of $5-10{ }^{\circ} \mathrm{C}$, and $\mathrm{pH}$ of 5-7.

\section{Diversity and abundance of MOB in sediment compared to gradient cultivation}

The methanotrophic diversity within the bands was low, as judged by the $p m o A$ clone libraries (Table 1). However, within a particular growth band, the growing community represented a varying bacterial diversity (e.g. high diversity in the case of band B and low diversity in the case of band C) as revealed by $16 \mathrm{~S}$ rRNA gene clone libraries.

The results of gradient $p m o A$ clone libraries were compared with the $p m o A$ clone library of Lake Constance littoral sediment prepared in this study. For comparison, sediment pmoA clone libraries had to be prepared using A189fmb661r primers because these primers are more specific in amplifying only the $p m o A$ gene and not the amo $A$ gene (Costello \& Lidstrom, 1999) and are known to cover more diversity of MOB (Bourne et al., 2001). The relative abundance of methanotrophs based on frequencies of $p m o A$ 
genes in the sediment clone library shows a dominance of type I methanotrophs (91\%). Within the type I MOB, clone group B1 or Methylobacter-like MOB dominate, at 65\%. In our gradient cultures, gradient clone group $\mathrm{C} 1$ lies within this dominant group, and we also isolated the methanotrophic strain LC 2, which is close to this group but has a distinct phylogenetic position. Another interesting group that we could cultivate was the gradient clones A1, A2 and $\mathrm{B} 1$ together with strain LC 1 , which are distantly related to sediment clone group B9. Among the type II MOB, the clone group B7 is dominant, and isolates of this group have been obtained by gradient (strains LC 3 and LC 4 , this study) and nongradient cultivation (Bussmann et al., 2004). Thus, gradient cultivation appears to broaden the diversity of cultivable methanotrophs substantially. So far, no MOB from other clone groups related to Methylococcus (clone groups B2 and B6) or clone groups related to uncultured methanotrophs (B8 and B10), which represent a total of $20 \%$ sediment clone library, have been cultivated from Lake Constance sediment. Further studies including gradient cultivation will aim at isolation of representatives of this group as well. In this context, strategies have to be developed to allow single colonies to grow in gradients, which has not been achieved successfully so far. This study is a further step in using gradient cultivation as a tool to cultivate novel methanotrophs by mimicking natural conditions in aquatic systems.

\section{Acknowledgements}

This study was supported by the Deutsche Forschungsgemeinschaft (SFB 454) and research funds of the Universität Konstanz. We wish to thank Thomas Grützner for assistance in the formaldehyde determination, Dirk Schmitt-Wagner and Ulrich Stingl for introduction to the ARB software package, and Michael Pester for valuable discussions.

\section{References}

Agrawal P \& Lim HC (1984) The growth dynamics of a methanol-utilizing bacterium L3 in a batch bioreactor. Biotechnol Bioeng 26: 1352-1363.

Altschul SF, Gish W, Miller W, Myers EW \& Lipman DJ (1990) Basic local alignment search tool. J Mol Biol 215: 403-410.

Amaral JA \& Knowles R (1995) Growth of methanotrophs in methane and oxygen counter gradients. FEMS Microbiol Lett 126: $215-220$.

Amaral JA, Archambault C, Richards SR \& Knowles R (1995) Denitrification associated with groups I and II methanotrophs in a gradient enrichment system. FEMS Microbiol Ecol 18: 289-298.
Auman AJ \& Lidstrom ME (2002) Analysis of sMMO-containing Type I methanotrophs in Lake Washington sediment. Environ Microbiol 4: 517-524.

Auman AJ, Stolyar S, Costello AM \& Lidstrom ME (2000) Molecular characterisation of methanotrophic isolates from freshwater lake sediment. Appl Environ Microbiol 66: 5259-5266.

Berestovskaya YY, Vasiléva LV, Chestnykh OV \& Zavarzin GA (2002) Methanotrophs of the psychrophilic microbial community of the Russian arctic tundra. Microbiology, Translated from Mikrobiologiya 71: 460-466.

Bourne DG, McDonald IR \& Murrell JC (2001) Comparison of pmoA PCR primer sets as tools for investigating methanotroph diversity in three Danish soils. Appl Environ Microbiol 67: 3802-3809.

Bowman J (2000) The methanotrophs - the families Methylococcaceae and Methylocystaceae. The Prokaryotes (Dworkin M, ed). Springer Verlag, New York (http:// link.springer-ny.com/link/service/books/10125).

Bussmann I (2005) Methane release through suspension of littoral sediment. Biogeochemistry 74: 283-302.

Bussmann I, Philipp B \& Schink B (2001) Factors influencing the cultivability of lake water bacteria. J Microbiol Meth 47: 41-50.

Bussmann I, Pester M, Brune A \& Schink B (2004) Preferential cultivation of type II methanotrophic bacteria from littoral sediments (Lake Constance). FEMS Microbiol Ecol 47: 179-189.

Costa C, Vecherskaya M, Dijkema C \& Stams AJM (2001) The effect of oxygen on methanol oxidation by an obligate methanotrophic bacterium studied by in vivo ${ }^{13} \mathrm{C}$ nuclear magnetic resonance spectroscopy. J Ind Microbiol Biotechnol 26: 9-14.

Costello AM \& Lidstrom ME (1999) Molecular characterisation of functional and phylogenetic genes from natural populations of methanotrophs in lake sediments. Appl Environ Microbiol 65: 5066-5074.

Costello AM, Auman AJ, Macalady JL, Scow KM \& Lidstrom ME (2002) Estimation of methanotroph abundance in a freshwater lake sediment. Environ Microbiol 4: 443-450.

Edwards U, Rogall T, Blöcker H, Emde M \& Böttger EC (1989) Isolation and direct complete nucleotide determination of entire genes. Characterization of a gene coding for $16 \mathrm{~S}$ ribosomal RNA. Nucleic Acids Res 17: 7843-7853.

Eisenstadt E, Carlton BC \& Brown BJ (1984) Gene mutation. Methods for General and Molecular Bacteriology (Gerhardt P, Murray RGE, Wood WA \& Krieg NR, eds), pp. 297-326. American Society of Microbiology, Washington, DC.

Erwin DP, Erickson IK, Delwiche ME, Colwell FS, Strap JL \& Crawford RL (2005) Diversity of oxygenase genes from methane- and ammonia-oxidizing bacteria in the eastern snake river Plain Aquifer. Appl Environ Microbiol 71: 2016-2025.

Felsenstein J (1989) PHYLIP, phylogeny inference package version 3.57c. Cladistics 5: 164-166. 
Flett RJ, Hamilton RD \& Campbell NER (1976) Aquatic acetylene-reduction techniques: solutions to several problems. Can J Microbiol 22: 43-51.

Graham DW, Chaudhary JA, Hanson RS \& Arnold RG (1993) Factors affecting competition between type I and type II methanotrophs in two-organism, continuous-flow reactors. Microbial Ecol 25: 1-17.

Grützner T \& Hasse H (2004) Solubility of formaldehyde and trioxane in aqueous solutions. J Chem Eng Data 49: 642-646.

Guiot E, Georges P, Brun A, Fontaine-Aupart MP, BellonFontaine MN \& Briandet R (2002) Heterogeneity of diffusion inside microbial biofilms determined by fluorescence correlation spectroscopy under two-photon excitation. Photochem Photobiol 75: 570-578.

Hanson RS \& Hanson TE (1996) Methanotrophic bacteria. Microbiol Rev 60: 439-471.

Hanson RS, Netrusov AI \& Tsuji K (1991) The obligate methanotrophic bacteria Methylococcus, Methylomonas and Methylosinus. The Prokaryotes, Vol. 3 (Balows A, Trüper HG, Dworkin M., Harder W \& Schleifer K-H, eds), pp. 2350-2364. Springer Verlag, New York.

Henckel T, Friedrich M \& Conrad R (1999) Molecular analyses of the methane-oxidizing microbial community in rice field soil by targeting the genes of the $16 \mathrm{~S}$ rRNA, particulate methane monooxygenase, and methanol dehydrogenase. Appl Environ Microbiol 65: 1980-1990.

Henckel T, Roslev P \& Conrad R (2000) Effects of $\mathrm{O}_{2}$ and $\mathrm{CH}_{4}$ on presence and activity of the indigenous methanotrophic community in rice field soil. Environ Microbiol 2: 666-679.

Heyer J, Malashenko Y, Berger U \& Budkova E (1984) Verbreitung methanotropher Bakterien. Z Allg Mikrobiol 24: 725-744.

Hilger HA, Cranford DF \& Barlaz MA (2000) Methane oxidation and microbial exopolymer production in landfill cover soil. Soil Biol Biochem 32: 457-467.

Holmes AJ, Owens NJP \& Murrell JC (1995) Detection of novel marine methanotrophs using phylogenetic and functional gene probes after methane enrichment. Microbiology 141: 1947-1955.

Hou CT, Lakin AI \& Patel RN (1978) Growth and polysaccharide production by Methlylocystis parvus OBBP on methanol. Appl Environ Microbiol 37: 800-804.

Joergensen L \& Degn H (1983) Mass spectrometric measurements of methane and oxygen utilization by methanotrophic bacteria. FEMS Microbiol Lett 20: 331-335.

Kreft JU \& Wimpenny JWT (2001) Effect of EPS on biofilm structure and function as revealed by an individual-based model of biofilm growth. Water Sci Technol 43: 135-141.

Lane DJ, Pace B, Olsen GJ, Stahl DA, Sogin ML \& Pace NR (1985) Rapid determination of $16 \mathrm{~S}$ ribosomal RNA sequences for phylogenetic analyses. Proc Natl Acad Sci USA 82: 6955-6959.

Lin J-L, Joye SB, Scholten JCM, Schäfer H, McDonald IR \& Murrell JC (2005) Analysis of methane monooxygenase genes in Mono Lake suggests that increased methane oxidation activity may correlate with a change in methanotroph community structure. Appl Environ Microbiol 71: 6458-6462.

Linton JD, Watts PD, Austin RM, Haugh DE \& Niekus HD (1986) The energetics and kinetics of extracellular polysaccharide production from methanol by micro-organisms possessing different pathways of $\mathrm{C} 1$ assimilation. J Gen Microbiol 132: 779-788.

Ludwig W, Strunk O, Westram R, et al. (2004) ARB: a software environment for sequence data. Nucleic Acids Res 32: 1363-1371.

Macalady JL, McMillan AMS, Dickens AF, Tyler SC \& Scow KM (2002) Population dynamics of type I and type II methanotrophic bacteria in rice soils. Environ Microbiol 4: 148-157.

McDonald IR, Kenna EM \& Murrell JC (1995) Detection of methanotrophic bacteria in environmental samples with the PCR. Appl Environ Microbiol 61: 116-121.

Nercessian O, Noyes E, Kalynzhnaya MG, Lidstrom ME \& Chistoserdova L (2005) Bacterial populations active in metabolism of $\mathrm{C} 1$ compounds in the sediment of Lake Washington, a freshwater lake. Appl Envir Microbiol 71: 6885-6899.

Ohkuma M \& Kudo T (1996) Phylogenetic diversity of the intestinal bacterial community in the termite Reticulitermes speratus. Appl Environ Microbiol 62: 461-468.

Pester M, Friedrich MW, Schink B \& Brune A (2004) pmoAbased analysis of methanotrophs in a littoral lake sediment reveals a diverse and stable community in a dynamic environment. Appl Environ Microbiol 70: 3138-3142.

Ren T, Roy RA \& Knowles R (2000) Production and consumption of nitric oxide by three methanotrophic bacteria. Appl Environ Microbiol 66: 3891-3897.

Rothfuss F \& Conrad R (1994) Development of a gas diffusion probe for the determination of methane concentrations and diffusion characteristics in flooded paddy soil. FEMS Microbiol Ecol 14: 307-318.

Schleheck D, Tindall BJ, Rossello-Mora R \& Cook AM (2004) Parvibaculum lavamentivoransgen. nov., sp. nov., a novel heterotroph that initiates catabolism of linear alkylbenzenesulfonate. Int J Syst Evol Microbiol 54: 1489-1497.

Shigematsu T, Hanada S, Eguchi M, Kamagata Y, Kanagava T \& Kurane R (1999) Soluble methane monooxygenase gene clusters from trichloroethylene-degrading Methylomonas sp. strains and detection of methanotrophs during in-situ bioremediation. Appl Environ Microbiol 65: 5198-5206.

Tourova TP, Omel chenko MV, Fegeding KV \& Vasiléva LV (1999) The phylogenetic position of Methylobacter psychrophilus sp. nov. Microbiology, Translated from Mikrobiologiya 68: 568-570.

Vorholt JA (2002) Cofactor-dependent pathways of formaldehyde oxidation in methylotrophic bacteria. Arch Microbiol 178: 239-249.

Wartiainen I, Hestnes AG, McDonald IR \& Svenning MM (2005) Methylobacter tundripaludum sp. nov., a methane-oxidising bacterium from arctic wetland soil on the Svalbard islands, Norway $\left(78^{\circ} \mathrm{N}\right)$. Int J Syst Evol Microbiol 56: 109-113. 
Weisburg WG, Barns SM, Pelletier DA \& Lane DJ (1991) 16S ribosomal DNA amplification for phylogenetic study. J Bacteriol 173: 697-703.

Whittenbury R, Phillips KC \& Wilkinson JF (1970) Enrichment, isolation and some properties of methane-utilizing bacteria. J Gen Microbiol 61: 205-218.

Widdel F (1988) Microbiology and ecology of sulfate - and sulfur-reducing bacteria. Biology of Anaerobic Microorganisms (Zehnder AJB, ed), pp. 469-585. John Wiley, New York.

Widdel F \& Pfennig N (1981) Studies on dissmilatory sulfatereducing bacteria that decompose fatty acids. I. Isolation of a new sulfate-reducer enriched with acetate from saline environments. Description of Desulfobacter postgatei gen nov sp. nov. Arch Microbiol 129: 395-400.
Wilkinson TG, Topiwala HH \& Hamer G (1974) Interactions in a mixed bacterial population growing on methane in continuous culture. Biotechnol Bioeng 16: 41-59.

Wilshusen JH, Hettiaratchi JPA, De Visscher A \& Saint-Fort R (2004) Methane oxidation and formation of EPS in compost: effect of oxygen concentrations. Environ Pollut 129: 305-314.

Wise MG, McArthur JV \& Shimkets LJ (1999) Methanotroph diversity in landfill soil: isolation of novel type I and type II methanotrophs whose presence was suggested by culture-independent $16 \mathrm{~S}$ ribosomal DNA analysis. Appl Environ Microbiol 65: 48874897. 